\title{
Improved model for solar heating of buildings
}

\author{
Bernt.Lie@hit.no \\ Telemark University College, Porsgrunn, Norway
}

\begin{abstract}
A considerable future increase in the global energy use is expected, and the effects of energy conversion on the climate are already observed. Future energy conversion should thus be based on resources that have negligible climate effects; solar energy is perhaps the most important of such resources.

The presented work builds on a previous complete model for solar heating of a house; here the aim to introduce ventilation heat recovery and improve on the hot water storage model. Ventilation heat recovery reduces the heat loss due to ventilation, as expected. Here, a recovery efficiency of 0.5 is used, although a more realistic number is perhaps 0.7 . The improved hot water storage model increases the exergy of the storage tank by assuming a vertical temperature distribution. Further improvements are possible by introducing a simple thermocline tracking algorithm, effectively allowing for variable volumes of the temperature zones in the hot water storage tank. Currently, the model does not allow for very good temperature control; this is due to a lack of freedom in the control inputs.
\end{abstract}

Keywords: Solar heating, Building models, Model efficiency, Control.

\section{Introduction}

The observed increase of greenhouse gases in the atmosphere in tandem with an increase in global temperature, has led to a concern about the temperature development for the rest of the century with the possible consequence of increased ocean level, more violent weather, etc. To counter these predictions, there is an emphasis on reducing the use of fossil fuel and thereby stop the increase in $\mathrm{CO}_{2}$ level of the atmosphere.

Solar energy is a freely available alternative to fossil energy. One possible way to utilize solar energy is to capture the irradiance in a solar collector, and store the energy by heating up water in a storage tank. Such hot water can be used for heating, for showering, etc. The intermittent nature of irradiance is partially handled by such storage of energy, but it is usually necessary to combine solar energy with auxiliary forms such as electricity or fossil fuel to ensure sufficient availability of power. Because of fluctuations in energy prices (spot marked), it may be possible to take advantage of predictions of irradiance to reduce the energy bill: if we know that tomorrow will be sunny, we can reduce the heating by electricity or fossil fuel - or at least make sure that we use such auxiliary forms when their cost is low.
The complexity level of models for solar heating of buildings range from simple models for energy planning over decades to detailed studies of the individual components in such systems. Of particular interest is the study of models suitable for on-line use. For large scale solar collector plants, concentrated solar power systems are used [18], while for domestic heating, flat plate solar collectors or evacuated collectors are cheaper. Here, we focus on domestic heating. The fitting of an industry standard flat plate solar collector model to experimental data is discussed in [12], while [21] and [20] discuss more complex models for transient studies. Both [5] and [7] give useful background in solar radiation and design of such collectors. Models of storage tanks are discussed e.g. in [7], see also [8], [2], and [19]. Software libraries with detailed building models are available, but for control studies, the discussion in [15], [16] is particularly relevant. Disturbances are important in building models. Domestic hot water load profiles are treated in [11]; seasonal variations and optimization is important for design [6] and [9]. Variation in solar irradiance and ambient temperature are typically measured; see e.g. [7]; day to day prediction of solar irradiance is treated in [1]. In [13], a relatively complete model structure for online use is given. With respect to on-line use of models, [4] use a simple model of a building together with prediction of outdoor temperature and varying electric spot prices to study possibilities for cost savings through advanced control, with emphasis on efficient algorithms, while [10], [17] and [14] discuss the use of Model Predictive Control of a system for thermal capturing of solar energy with auxiliary energy supply.

Although relatively complete in structure, the model in [13] has a number of limitations. (i) Heat integration during ventilation is not included, and heat loss through ventilation is of major importance, (ii) the water storage model is homogeneous in temperature; real storage tanks may exhibit a large spatial variation in temperature, (iii) heat transfer is computed using fixed numbers, but heat transfer varies with fluid flow, (iv) variation in fluid flow rates is not included, (v) the solar collector model is static. It is of interest to improve on the model in [13]; in this paper, points (i) and (ii) above are addressed. Stratification is known to occur in hot water tanks. In [19], a plug flow model modified with thermal diffusion is used to approximate this effect; a very high order discretized model (600 states) is used as a reference model, and a lower order model with some 60 states and adaptive thermocline front tracking is proposed. The results do, however, indicate that for a storage tank with indirect heating via a heat exchanger, a low order model, possibly with thermocline front tracking, may suffice. It is quite common to approximate the storage tank with $2-3$ 


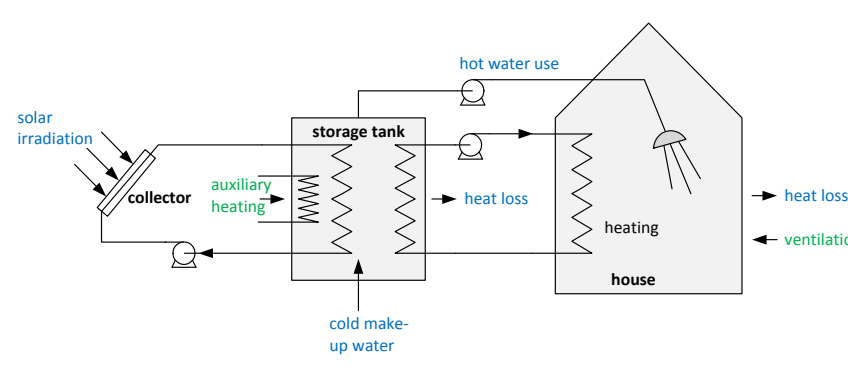

Figure 1: Blue font indicates disturbance variable, while green font indicates control variable. Heat losses are due to temperature differences to ambient temperatures. The storage tank is assumed to be instantly re-filled with cold make-up water, which may have a varying temperature.

well mixed, fixed size tanks. ${ }^{1}$

The paper is organized as follows. First, a description of the system with solar heating, storage tank and building is given, with some background information. Next, simple modifications of the unit models for the storage tank and the ventilation system are presented and discussed. Then the modified full model is given, and simulation results are given. Finally, some conclusions are drawn.

\section{System description}

\subsection{System elements}

The system for mixed solar and electric (auxiliary) heating of a domestic building as reported in [13], is depicted in Figure 1. The reason for introducing heat exchangers to separate the fluids of the collector circuit and the heating circuit from the utility hot water of the storage tank ("indirect heating"), is to allow for use of anti freeze and algae reducing components in these circuits. The reported model in [13] had a number of deficiencies, and here an improved description of the ventilation system and the storage tank will be introduced.

A simple improvement of the ventilation system could be to introduce an energy recovery efficiency $\eta_{\mathrm{v}}$. A storage tank with heat exchangers is depicted in Figure 2, and is modified to include stratification in comparison with [13]. The water in the storage tank consists of a cold zone of more or less homogeneous temperature at the bottom separated by a thermocline (large temperature gradient) from the hot zone of more or less homogeneous temperature at the top. This is an improvement compared to the storage tank in [13] where the storage tank was assumed to be perfectly well mixed. It is still assumed that the tube side temperature is constant throughout, i.e. that the collector fluid has homogeneous temperature throughout the tube side and that the floor fluid has homogeneous temperature throughout the tube side. The auxiliary heating has, however, been modified so that it only operates in the hot zone.

${ }^{1}$ Suggested in personal communication by U. Eicker.

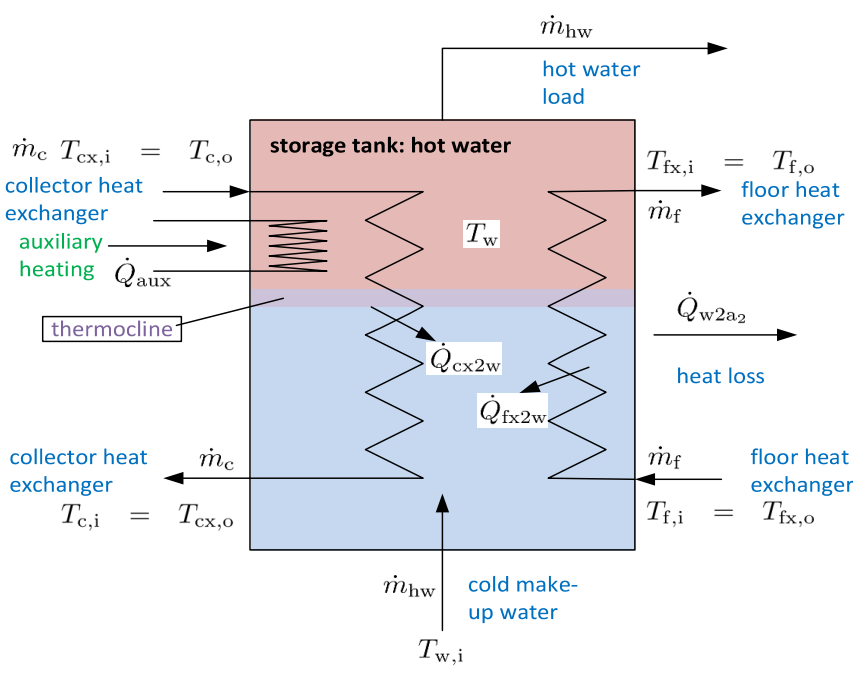

Figure 2: Sketch of storage tank, including thermocline which separates the cold zone (bottom; blue color) and the hot zone (top; red color).

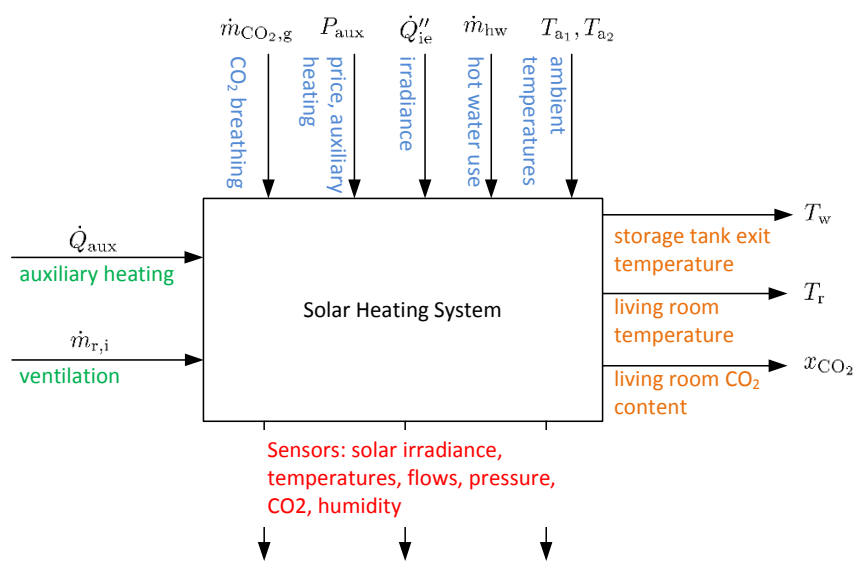

Figure 3: Functional description of the solar heating system with auxiliary heating input.

\subsection{Functional description}

From a system theoretic point of view, it is useful to present the system as a block diagram with inputs and outputs inputs and outputs will vary with time; Figure 3 illustrates this causal relationship with disturbances on the top of the block, control inputs (manipulating inputs) at the left side, while performance outputs (orange) are shown on the right side of the system block and available sensor signals (red) at the bottom of the block. This functional description is the same as in [13], and is unaffected by the modification of the ventilation system and the storage tank.

\section{Unit models}

\subsection{Storage tank thermal energy balance}

A thermocline as indicated in Fig. 2 is the result of density variations wrt. temperature, and buoyancy effects thereof. In general, such a thermal stratification is complex, and requires a description involving mass, momentum and energy balances in 3D. For on-line use, a common simplification 


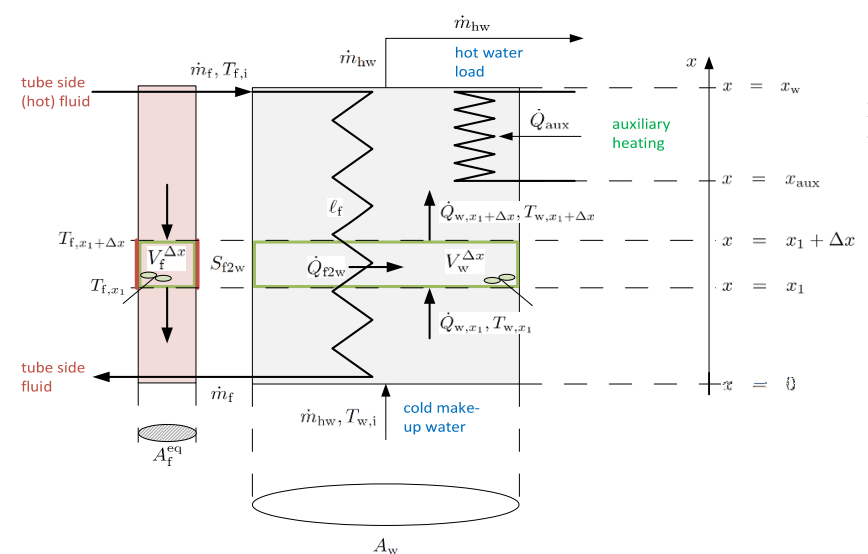

Figure 4: Principle layout of storage tank.

is to assume that the feed/exit diffusers are constructed so that $1 \mathrm{D}$ models are reasonably accurate, and neglect the momentum balance. Furthermore, it is common to assume the density is constant. This leads to a 1D energy balance, [19]. In the sequel, if quantity $q$ is an extensive quantity, $\dot{q}$ denotes the flow rate of $q$. Furthermore, for a general quantity $q, q^{\prime}$ denotes the quantity per length unit, $q^{\prime \prime}$ denotes the quantity per unit area (length squared), etc. Figure 4 illustrates the principle layout of the storage tank, with stored water ("shell side" of heat exchanger), subscript w, in heat exchange with fluid ("tube side"), subscript $\mathrm{f}$.

\subsection{Storage tank distributed model}

In Fig. 4, a 1D distribution of the temperature in the vertical direction $(x \in[0, H])$ is indicated, with discretization into well mixed slices of height $\Delta x$. The well mixed volume of water in the interval $x \in\left[x_{1}, x_{1}+\Delta x\right]$ is indicated by $V_{\mathrm{w}}^{\Delta x}$, while the well mixed volume of the heat exchanging fluid in the same $x$ interval is indicated by $V_{\mathrm{f}}^{\Delta x}$. The cross sectional area of the water tank, orthogonal to the $x$ axis, is $A_{\mathrm{w}}$. For the tube side of the heat exchanger coil, an equivalent cross sectional area is $A_{\mathrm{f}}^{\text {eq }}$ defined such that $V_{\mathrm{f}}^{\Delta x}=A_{\mathrm{f}}^{\mathrm{eq}} \Delta x$.

By letting $\Delta x \rightarrow 0$, the complete model with a tube side hot fluid can be summarized as

$$
\begin{aligned}
\frac{m_{\mathrm{w}} \hat{c}_{p \mathrm{w}}}{x_{\mathrm{w}}} \frac{\partial T_{\mathrm{w}}}{\partial t}= & -\dot{m}_{\mathrm{hw}} \hat{c}_{p \mathrm{w}} \frac{\partial T_{\mathrm{w}}}{\partial x}+\dot{Q}_{\mathrm{f} 2 \mathrm{w}}^{\prime} \\
& +\dot{Q}_{\mathrm{aux}}^{\prime}-A_{\mathrm{w}} \frac{\partial \dot{Q}_{\mathrm{w}}^{\prime \prime}}{\partial x} \\
\dot{Q}_{\mathrm{w}}^{\prime \prime}= & -k_{\mathrm{w}} \frac{\partial T_{\mathrm{w}}}{\partial x} \\
\frac{m_{\mathrm{f}} \hat{c}_{p \mathrm{f}}}{x_{\mathrm{w}}} \frac{\partial T_{\mathrm{f}}}{\partial t}= & \dot{m}_{\mathrm{f}} \hat{c}_{p \mathrm{f}} \frac{\partial T_{\mathrm{f}}}{\partial x}-\dot{Q}_{\mathrm{f} 2 \mathrm{w}}^{\prime}
\end{aligned}
$$

where

$$
\dot{Q}_{\mathrm{f} 2 \mathrm{w}}^{\prime}=\frac{\left.U A\right|_{\mathrm{f} 2 \mathrm{w}}}{x_{\mathrm{w}}}\left(T_{\mathrm{f}}-T_{\mathrm{w}}\right)
$$

with boundary conditions

$$
\begin{aligned}
T_{\mathrm{w}}(t, x=0) & =T_{\mathrm{w}, \mathrm{i}} \\
\dot{Q}_{\mathrm{w}}^{\prime \prime}\left(t, x=x_{\mathrm{w}}\right) & =0 \\
T_{\mathrm{f}}\left(t, x=x_{\mathrm{w}}\right) & =T_{\mathrm{f}, \mathrm{i}}
\end{aligned}
$$

and initial conditions given by $T_{\mathrm{w}}(t=0, x), \dot{Q}_{\mathrm{w}}^{\prime \prime}(t=0, x)$ and $T_{\mathrm{f}}(t=0, x)$. If the tube side fluid is cold, we need to reverse the tube side fluid and replace $\dot{m}_{\mathrm{f}}$ with $-\dot{m}_{\mathrm{f}}$, with boundary condition at $x=0 ; T_{\mathrm{f}}(t, x=0)=T_{\mathrm{f}, \mathrm{i}}$.

By assuming steady operation, the model simplifies to

$$
\begin{aligned}
\frac{d \dot{Q}_{\mathrm{w}}^{\prime \prime}}{d x}= & \frac{\dot{m}_{\mathrm{hw}} \hat{c}_{p \mathrm{w}}}{k_{\mathrm{w}} A_{\mathrm{w}}} \dot{Q}_{\mathrm{w}}^{\prime \prime}+\frac{\left.U A\right|_{\mathrm{f} 2 \mathrm{w}}}{A_{\mathrm{w}} x_{\mathrm{w}}}\left(T_{\mathrm{f}}-T_{\mathrm{w}}\right) \\
& +\frac{1}{A_{\mathrm{w}}} \dot{Q}_{\mathrm{aux}}^{\prime} \\
\frac{d T_{\mathrm{w}}}{d x}= & -\frac{1}{k_{\mathrm{w}}} \dot{Q}_{\mathrm{w}}^{\prime \prime} \\
\frac{d T_{\mathrm{f}}}{d x}= & \frac{\left.U A\right|_{\mathrm{f} 2 \mathrm{w}}}{x_{\mathrm{w}} \dot{m}_{\mathrm{f}} \hat{c}_{p \mathrm{f}}}\left(T_{\mathrm{f}}-T_{\mathrm{w}}\right)
\end{aligned}
$$

with

$$
\begin{aligned}
\dot{Q}_{\mathrm{w}, x=x_{\mathrm{w}}}^{\prime \prime} & =0 \\
T_{\mathrm{w}, x=0} & =T_{\mathrm{w}, \mathrm{i}} \\
T_{\mathrm{f}, x=x_{\mathrm{w}}} & =T_{\mathrm{f}, \mathrm{i}} .
\end{aligned}
$$

The model in Eqs. 1-3 can be discretized in space by reversing the $\Delta x \rightarrow 0$ limit.

\subsection{Storage tank concentrated model}

Next, introduce the hypothesis that the tube side fluid temperature $T_{\mathrm{f}}$ varies little through the coil, while the shell side water temperature $T_{\mathrm{w}}$ is more or less homogeneous in the region $\left[0, x_{\text {aux }}\right)$ and is different but more or less homogeneous within the region $\left[x_{\mathrm{aux}}, x_{\mathrm{w}}\right]$. This hypothesis leads to a concentrated model

$$
\begin{aligned}
\frac{d T_{\mathrm{w}, \ell}}{d t}= & \frac{\dot{m}_{\mathrm{hw}} \hat{c}_{p \mathrm{w}}}{m_{\mathrm{w}} \frac{x_{\mathrm{aux}}}{x_{\mathrm{w}}} \hat{c}_{p \mathrm{w}}}\left(T_{\mathrm{w}, \mathrm{i}}-T_{\mathrm{w}, \ell}\right) \\
& +\frac{\left.U A\right|_{\mathrm{f} 2 \mathrm{w}} \frac{x_{\mathrm{aux}}}{x_{\mathrm{w}}}}{m_{\mathrm{w}} \frac{x_{\mathrm{aux}}}{x_{\mathrm{w}}} \hat{c}_{p \mathrm{w}}}\left(T_{\mathrm{f}}-T_{\mathrm{w}, \ell)}\right. \\
\frac{d T_{\mathrm{w}, \mathrm{u}}}{d t}= & \frac{\dot{m}_{\mathrm{hw}} \hat{c}_{p \mathrm{w}}}{m_{\mathrm{w}} \frac{x_{\mathrm{w}}-x_{\mathrm{aux}}}{x_{\mathrm{w}}} \hat{c}_{p \mathrm{w}}}\left(T_{\mathrm{w}, \ell}-T_{\mathrm{w}, \mathrm{u}}\right) \\
& +\frac{\left.U A\right|_{\mathrm{f} 2 \mathrm{w}} \frac{x_{\mathrm{w}}-x_{\mathrm{aux}}}{x_{\mathrm{w}}}}{m_{\mathrm{w}} \frac{x_{\mathrm{w}}-x_{\mathrm{aux}}}{x_{\mathrm{w}}} \hat{c}_{p \mathrm{w}}}\left(T_{\mathrm{f}}-T_{\mathrm{w}, \mathrm{u}}\right) \\
\frac{d T_{\mathrm{f}}}{d t}= & +\frac{1}{m_{\mathrm{w}} \frac{x_{\mathrm{w}}-x_{\mathrm{aux}}}{x_{\mathrm{w}}} \hat{c}_{p \mathrm{w}}} \dot{Q}_{\mathrm{aux}} \\
& \dot{m}_{\mathrm{f}} \hat{c}_{p \mathrm{f}}\left(T_{\mathrm{f}, \mathrm{i}}-T_{\mathrm{f}}\right) \\
& -\frac{\left.U A\right|_{\mathrm{f} 2 \mathrm{w}} \frac{x_{\mathrm{aux}}}{x_{\mathrm{w}}}}{m_{\mathrm{f}} \hat{c}_{p \mathrm{f}}}\left(T_{\mathrm{f}}-T_{\mathrm{w}, \ell}\right) \\
& -\frac{\left.U A\right|_{\mathrm{f} 2 \mathrm{w}} \frac{x_{\mathrm{w}}-x_{\mathrm{aux}}}{x_{\mathrm{w}}}}{m_{\mathrm{f}} \hat{c}_{p \mathrm{f}}}\left(T_{\mathrm{f}}-T_{\mathrm{w}, \mathrm{u}}\right),
\end{aligned}
$$

with initial states $T_{\mathrm{w}, \ell}, T_{\mathrm{w}, \mathrm{u}}$ and $T_{\mathrm{f}}$ given at zero time.

By assuming steady operation, the concentrated model reduces to linear equations, and can easily be reformulated into the matrix form

$$
M\left(\begin{array}{c}
T_{\mathrm{w}, \ell} \\
T_{\mathrm{w}, \mathrm{u}} \\
T_{\mathrm{f}}
\end{array}\right)=\left(\begin{array}{c}
\dot{m}_{\mathrm{hw}} \hat{c}_{p \mathrm{w}} T_{\mathrm{w}, \mathrm{i}} \\
\dot{Q}_{\mathrm{aux}} \\
\dot{m}_{\mathrm{f}} \hat{c}_{p \mathrm{f}} T_{\mathrm{f}, \mathrm{i}}
\end{array}\right)
$$


Table 1: Nominal parameters for storage tanke of solar heating system.

\begin{tabular}{lll}
\hline Parameter & Value & Unit \\
\hline$A_{\mathrm{w}}$ & $x_{\mathrm{w}}^{2}$ & $\mathrm{~m}^{2}$ \\
$A_{\mathrm{f}}^{\mathrm{eq}}$ & $\frac{\pi r_{\mathrm{p}}^{2} \ell_{\mathrm{f}}}{x_{\mathrm{w}}}$ & $\mathrm{m}^{2}$ \\
$\hat{c}_{\mathrm{ff}}$ & 3.5 & $\frac{\mathrm{kJ}}{\mathrm{kg} \mathrm{K}}$ \\
$\hat{c}_{p \mathrm{w}}$ & 4.19 & $\frac{\mathrm{kJ}}{\mathrm{kgK}}$ \\
$k_{\mathrm{w}}$ & $0.6 \times 10^{-3}$ & $\frac{\mathrm{kW}}{\mathrm{mK}}$ \\
$\ell_{\mathrm{f}}$ & 30 & $\mathrm{~m}$ \\
$m_{\mathrm{w}}$ & $60 \cdot N_{\mathrm{pers}}$ & $\mathrm{kg}$ \\
$N_{\mathrm{pers}}$ & 2 & - \\
$r_{\mathrm{p}}$ & $\frac{13}{2} \times 10^{-3}$ & $\mathrm{~m}$ \\
$S_{\mathrm{f} 2 \mathrm{w}}$ & $2 \pi r_{\mathrm{p}} \cdot \ell_{\mathrm{f}}$ & $\mathrm{m}$ \\
$U_{\mathrm{f} 2 \mathrm{w}}$ & 0.25 & $\frac{\mathrm{kW}}{\mathrm{m}^{2} \mathrm{~K}}$ \\
$x_{\mathrm{aux}}$ & $\frac{3}{4} x_{\mathrm{w}}$ & $\mathrm{m}$ \\
$x_{\mathrm{w}}$ & $\sqrt[3]{\frac{m_{\mathrm{w}}}{\rho_{\mathrm{w}}}}$ & $\mathrm{m}$ \\
$\rho_{\mathrm{f}}$ & 1060 & $\mathrm{~kg} / \mathrm{m}^{3}$ \\
$\rho_{\mathrm{w}}$ & $10^{3}$ & $\mathrm{~kg} / \mathrm{m}^{3}$ \\
$\wp_{\mathrm{w}}$ & $\frac{S_{\mathrm{f} 2 \mathrm{w}}}{x_{\mathrm{w}}}$ & $\mathrm{m}$ \\
\hline
\end{tabular}

where the elements of matrix $M$ are:

$$
\begin{aligned}
M_{11} & =\dot{m}_{\mathrm{hw}} \hat{c}_{p \mathrm{w}}+\left.U A\right|_{\mathrm{f} 2 \mathrm{w}} \frac{x_{\mathrm{aux}}}{x_{\mathrm{w}}} \\
M_{12} & =0 \\
M_{13} & =-\left.U A\right|_{\mathrm{f} 2 \mathrm{w}} \frac{x_{\mathrm{aux}}}{x_{\mathrm{w}}} \\
M_{21} & =-\dot{m}_{\mathrm{hw}} \hat{c}_{p \mathrm{w}} \\
M_{22} & =\dot{m}_{\mathrm{hw}} \hat{c}_{p \mathrm{w}}+\left.U A\right|_{\mathrm{f} 2 \mathrm{w}} \frac{x_{\mathrm{w}}-x_{\mathrm{aux}}}{x_{\mathrm{w}}} \\
M_{23} & =-\left.U A\right|_{\mathrm{f} 2 \mathrm{w}} \frac{x_{\mathrm{w}}-x_{\mathrm{aux}}}{x_{\mathrm{w}}} \\
M_{31} & =-\left.U A\right|_{\mathrm{f} 2 \mathrm{w}} \frac{x_{\mathrm{aux}}}{x_{\mathrm{w}}} \\
M_{32} & =-\left.U A\right|_{\mathrm{f} 2 \mathrm{w}} \frac{x_{\mathrm{w}}-x_{\mathrm{aux}}}{x_{\mathrm{w}}} \\
M_{33} & =\dot{m}_{\mathrm{f}} \hat{c}_{p \mathrm{f}}+\left.U A\right|_{\mathrm{f} 2 \mathrm{w}} \frac{x_{\mathrm{aux}}}{x_{\mathrm{w}}} .
\end{aligned}
$$

\section{Storage tank simulation}

\subsection{Parameters and operating conditions}

Examples of parameter values for the storage tank are given in Table 1.

Examples of operating conditions are given in Table 2.

In Table 2, $T_{\mathrm{c}}$ is the temperature of the concentrated model.

\subsection{Steady operation}

The two point boundary value steady models are solved using routine bvp $4 \mathrm{C}$ in MATLAB of The MathWorks. ${ }^{2}$ Figure 5 illustrates the steady temperatures in the storage tank $\left(T_{\mathrm{w}}\right)$ and the tube side of the heat exchanger $\left(T_{\mathrm{f}}\right)$ when $\dot{Q}_{\mathrm{aux}}=2 \mathrm{~kW}$.
Table 2: Nominal operating conditions for storage tank. $\mu_{x}$ is the Heaviside function.

\begin{tabular}{lll}
\hline Quantity & Value & Unit \\
\hline$\dot{m}_{\mathrm{f}}$ & $\frac{2 \times 10^{3}}{3600}$ & $\mathrm{~kg} / \mathrm{s}$ \\
$\dot{m}_{\mathrm{hw}}$ & $\frac{50}{24 \cdot 3600} N_{\text {pers }}$ & $\mathrm{kg} / \mathrm{s}$ \\
$\dot{Q}_{\mathrm{aux}}$ & $2 \mu_{x_{\text {aux }}}$ & $\mathrm{kW}$ \\
$\dot{Q}_{\mathrm{aux}}^{\prime}$ & $\frac{\dot{Q}_{\text {aux }}}{x_{\mathrm{w}}-x_{\mathrm{aux}}}$ & $\frac{\mathrm{kW}}{\mathrm{m}}$ \\
$T_{\mathrm{f}, \mathrm{i}}$ & 70 & ${ }^{\circ} \mathrm{C}$ \\
$T_{\mathrm{w}, \mathrm{i}}$ & 10 & ${ }^{\circ} \mathrm{C}$ \\
\hline$T_{\mathrm{f}}(t=0, x)$ & $T_{\mathrm{f}, \mathrm{i}}$ & ${ }^{\circ} \mathrm{C}$ \\
$T_{\mathrm{c}}(t=0)$ & $T_{\mathrm{f}, \mathrm{i}}$ & ${ }^{\circ} \mathrm{C}$ \\
$T_{\mathrm{w}}(t=0, x)$ & $T_{\mathrm{w}, \mathrm{i}}$ & ${ }^{\circ} \mathrm{C}$ \\
$T_{\mathrm{w}, \ell}(t=0)$ & $T_{\mathrm{w}, \mathrm{i}}$ & ${ }^{\circ} \mathrm{C}$ \\
$T_{\mathrm{w}, \mathrm{u}}(t=0)$ & $T_{\mathrm{w}, \mathrm{i}}$ & ${ }^{\circ} \mathrm{C}$ \\
\hline
\end{tabular}
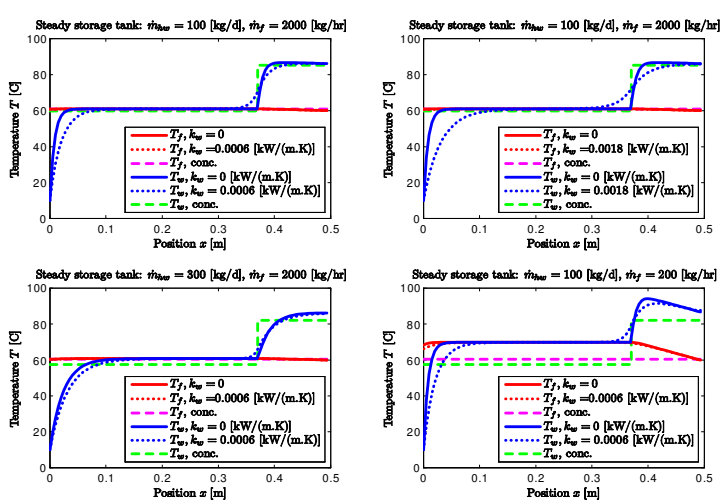

Figure 5: Steady temperatures in storage system: $T_{\mathrm{w}}$ (blue, concentrated: green) and $T_{\mathrm{f}}$ (distributed: red, concentrated: magenta); without diffusion (solid) and with diffusion (dotted). Auxiliary heat $\dot{Q}_{\text {aux }}=2 \mathrm{~kW}$. Subplot $(1,1)$ : nominal case; subplot $(1,2)$ : tripled diffusion coefficient $k_{\mathrm{w}}$; subplot $(2,1)$ : tripled hot water consumption $\dot{m}_{\mathrm{hw}}$; subplot $(2,2)$ : $10 \%$ tube side flow $\dot{m}_{\mathrm{f}}$.

\footnotetext{
${ }^{2}$ See www . mathworks.com.
} 

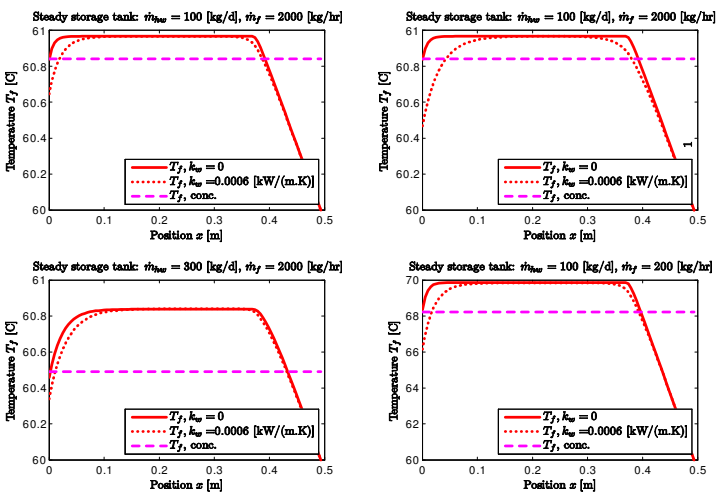

Figure 6: Details of steady tube side temperature $T_{\mathrm{f}}$ (distributed: red, concentrated: magenta); without diffusion (solid) and with diffusion (dotted). Auxiliary heat $\dot{Q}_{\text {aux }}=2 \mathrm{~kW}$. Subplot $(1,1)$ : nominal case; subplot $(1,2)$ : tripled diffusion coefficient $k_{\mathrm{w}}$; subplot $(2,1)$ : tripled hot water consumption $\dot{m}_{\mathrm{hw}}$; subplot $(2,2): 10 \%$ tube side flow $\dot{m}_{\mathrm{f}}$.

Figure 6 gives a more detailed view of the tube side temperature with and without diffusion, with $\dot{Q}_{\text {aux }}=2 \mathrm{~kW}$.

The results in plot $(1,1)$ of Figure 5 seem to indicate that the nominal storage tank system with volume given by $x \in\left[0, x_{\text {aux }}\right)$ is relatively well mixed - except perhaps for a small region near $x=0$, and that the nominal system and volume given by $x \in\left[x_{\mathrm{aux}}, x_{\mathrm{w}}\right]$ is relatively well mixed. In other words: it may be possible to simplify the model into a two compartment model. Likewise, the tube side seems to have a relatively constant temperature throughout, leading to a third compartment. However, if the heat diffusion is important (plot $(1,2)$ in the figures), or the hot water consumption $\dot{m}_{\mathrm{hw}}$ increases dramatically (plot $(2,1)$ in the figures), or the flow rate $\dot{m}_{\mathrm{f}}$ of the hot water fluid decreases dramatically (plot $(2,2)$ ), then such a coarse three compartment model is probably too simple. It should be remembered that these conclusions are based on a steady model. It remains to see whether the inertia of the system can be captured by a coarse three compartment model.

\subsection{Transient operation}

The dynamic models are solved using the solver ode15s in MATLAB of The MathWorks. ${ }^{3}$ Solving the discretized dynamic model with $N=50$ slices and for the nominal conditions, leads to the results in Figs. 7-8.

Comparisons of the transients of the distributed model with the concentrated model are given Figs. 9-10.

If we reduce the tube fluid flow rate $\dot{m}_{\mathrm{f}}$ to $10 \%$ of the nominal value, the results are as in Figs. 11-12.

Finally, it is of interest how changing various quantities affect the system when the system starts from steady state. Figures $13-14$ show the effect of a $10^{\circ} \mathrm{C}$ drop in $T_{\mathrm{f}, \mathrm{i}}$ when starting from nomial steady state.

Changes in other inputs show minor response and relatively similar response in the distributed model and the concentrated model, except for changes in $\dot{m}_{\mathrm{hw}}$ where the re-

\footnotetext{
${ }^{3}$ See www. mathworks. com.
}

Storage tank water temperature

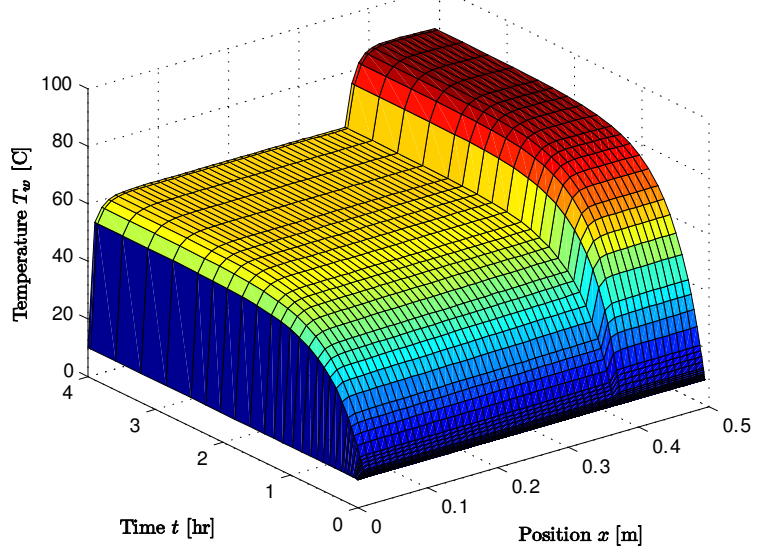

Figure 7: Transient temperature distribution $T_{\mathrm{w}} ; N=50$. Conditions as in Figs. 5-6, subplot $(1,1)$.

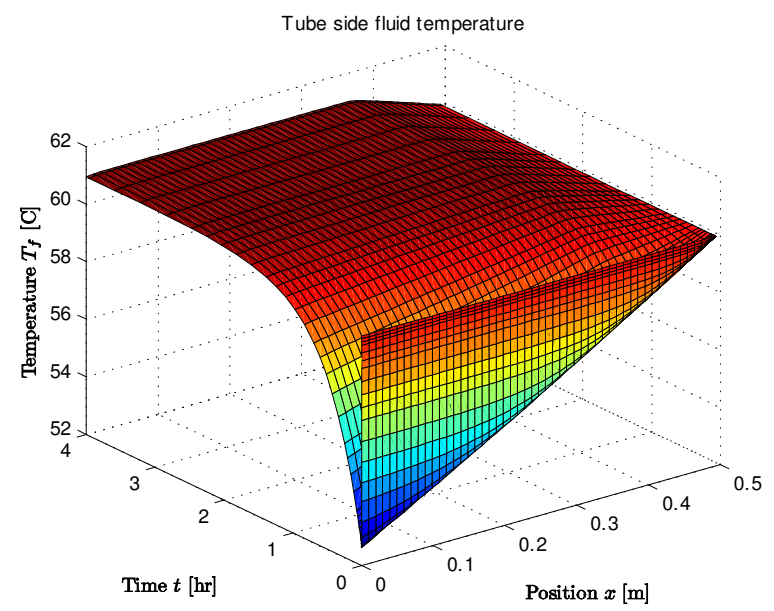

Figure 8: Transient temperature distribution $T_{\mathrm{f}} ; N=50$. Conditions as in Figs. 5-6, subplot $(1,1)$.

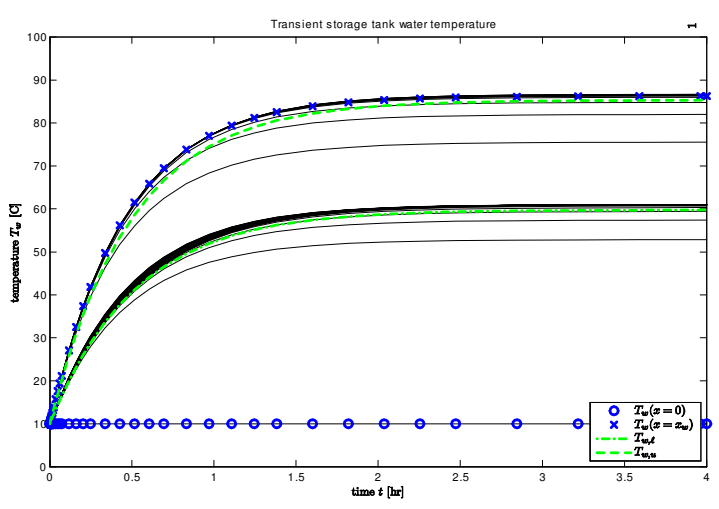

Figure 9: Transient storage tank water temperature distribution (solid black), with indications of inlet temperature $T_{\mathrm{w}, \mathrm{i}}$ (circle, blue) and outlet temperature $T_{\mathrm{w}}\left(x=x_{\mathrm{w}}\right)(\mathrm{x}$, blue), as well as lower concentrated temperature $T_{\mathrm{w}, \ell}$ (dash-dot, green) and upper concentrated temperature $T_{\mathrm{w}, \mathrm{u}}$ (dashed, green). Conditions as in Figs. 5-6, subplot $(1,1)$. 


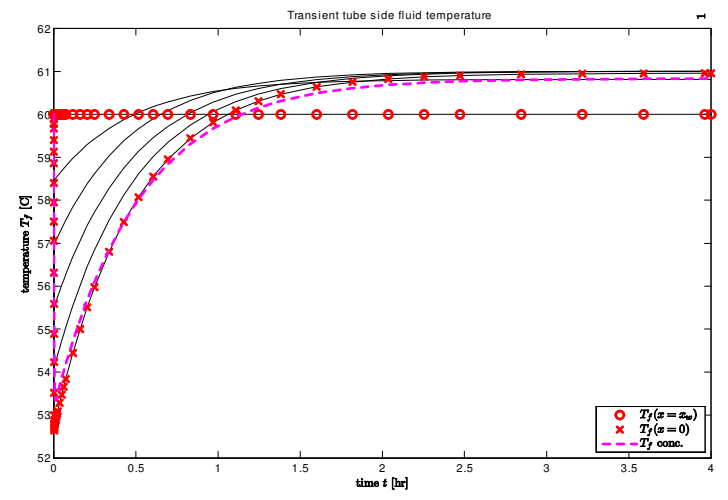

Figure 10: Transient tube side fluid temperature distribution (solid black), with indications of inlet temperature $T_{\mathrm{f}, \mathrm{i}}$ (circle, red) and outlet temperature $T_{\mathrm{f}}(x=0)(\mathrm{x}, \mathrm{red})$, as well as concentrated model temperature $T_{\mathrm{f}}$ (dashed, magenta). Conditions as in Figs. 5-6, subplot $(1,1)$.

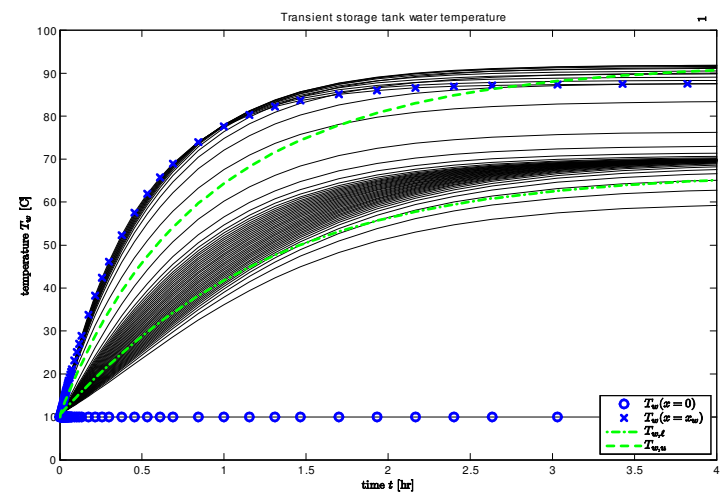

Figure 11: Transient storage tank water temperature distribution (solid black), with indications of inlet temperature $T_{\mathrm{w}, \mathrm{i}}$ (circle, blue) and outlet temperature $T_{\mathrm{w}}\left(x=x_{\mathrm{w}}\right)$ (x, blue), as well as lower concentrated temperature $T_{\mathrm{w}, \ell}$ (dash-dot, green) and upper concentrated temperature $T_{\mathrm{w}, \mathrm{u}}$ (dashed, green). Conditions as in Figs. 5-6, subplot $(2,2)$.

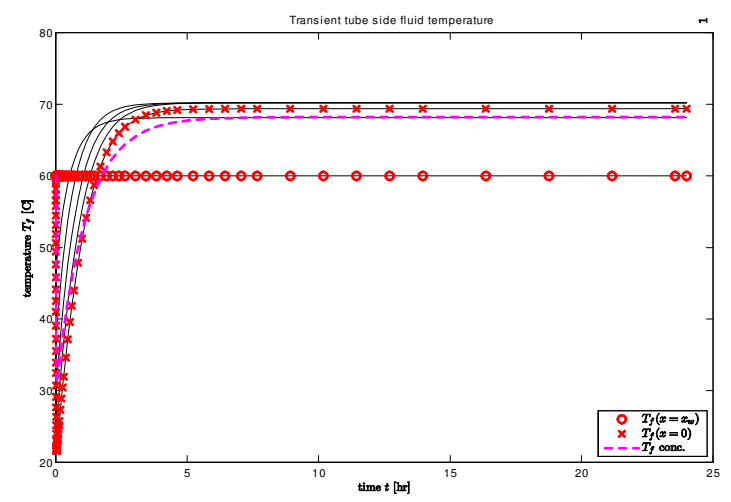

Figure 12: Transient tube side fluid temperature distribution (solid black), with indications of inlet temperature $T_{\mathrm{f}, \mathrm{i}}$ (circle, red) and outlet temperature $T_{\mathrm{f}}(x=0)(\mathrm{x}, \mathrm{red})$, as well as concentrated model temperature $T_{\mathrm{f}}$ (dashed, magenta). Conditions as in Figs. 5-6, subplot $(2,2)$.

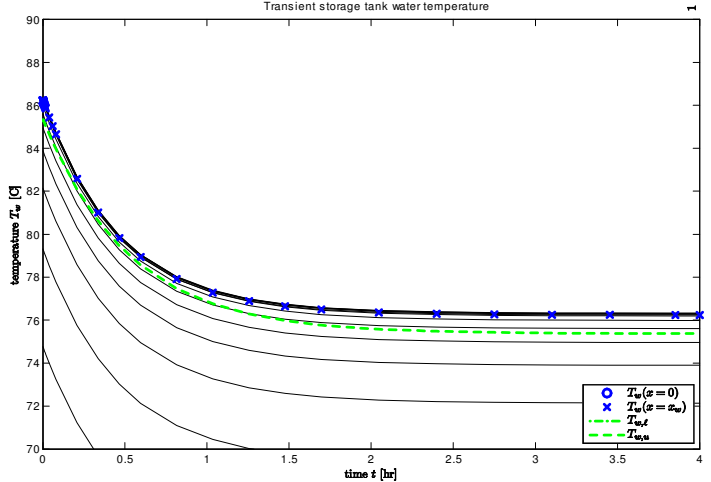

Figure 13: Transient storage tank water temperature distribution (solid black), when starting from nominal steady state, and experiencing a $10^{\circ} \mathrm{C}$ drop in inlet temperature $T_{\mathrm{w}, \mathrm{i}}$. Response in outlet temperature $T_{\mathrm{w}}\left(x=x_{\mathrm{w}}\right)$ (x, blue), as well as upper concentrated temperature $T_{\mathrm{w}, \mathrm{u}}$ (dashed, green).

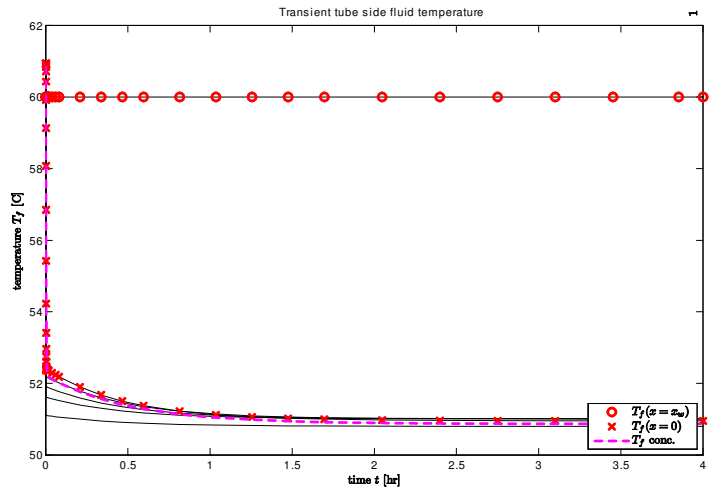

Figure 14: Transient tube side fluid temperature distribution (solid black), when starting from nominal steady state, and experiencing a $10^{\circ} \mathrm{C}$ drop in inlet temperature $T_{\mathrm{f}, \mathrm{i}}$. Response in inlet temperature $T_{\mathrm{f}, \mathrm{i}}$ (circle, red) and outlet temperature $T_{\mathrm{f}}(x=0)(\mathrm{x}$, red $)$, as well as concentrated model temperature $T_{\mathrm{f}}$ (dashed, magenta). 


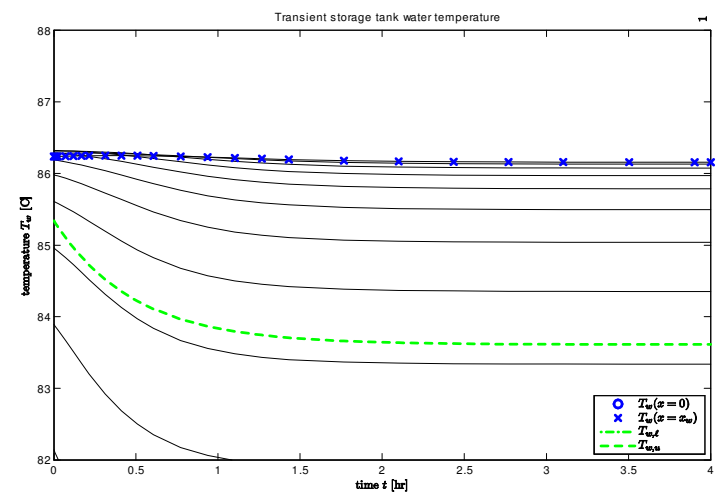

Figure 15: Transient storage tank water temperature distribution (solid black), when starting from nominal steady state, and experiencing a doubling of the hot water mass flow $\dot{m}_{\mathrm{hw}}$. Response in outlet temperature $T_{\mathrm{w}}\left(x=x_{\mathrm{w}}\right)$ (x, blue), as well as upper concentrated temperature $T_{\mathrm{w}, \mathrm{u}}$ (dashed, green).

sponse in $T_{\mathrm{w}}\left(x=x_{\mathrm{w}}\right)$ is minor for the distributed model and relatively pronounced for the concentrated model, Fig. 15.

\subsection{Comparing models}

In [19], a simple model of a water storage tank with stratification is discussed, and an adaptive algorithm for tracking the thermocline is developed. Tracking of the thermocline is particularly important for the case of recirculating the heated water into the bottom of the storage tank. However, when the energy in the heated water is transferred through a heat exchanger, as discussed in this work, the thermocline will be much less pronounced.

With a heat exchanger, and in steady operation, Figure 6 indicates that assumptions of constant storage tank water temperature below the auxiliary heating region as well as a different and constant temperature in the auxiliary heating region, and constant tube fluid temperature throughout may be reasonably good for most conditions - except for (unrealistically) low flow rate for the tube fluid. Figures 8-10 indicate that under nominal conditions, the reduced order 3 state model captures both the steady state conditions and the inertia of the system reasonably well. However, in the case of low flow rate for the tube fluid, the reduced order model has too slow dynamics for the storage tank effluent temperature. Figures 13-15 indicate that for most input changes, the concentrated 3 state model is reasonably good, except for at capturing the outlet temperature for changes in the hot water flow rate $\dot{m}_{\mathrm{hw}}$.

The plots of the transients of the fluid temperature $T_{\mathrm{f}}$, Figs. 8, 10 and 12 do indicate the presence of some fast dynamics and thus a stiff system, and it is probably possible to reduce the order of the model. This possibility is not pursued here, though, and the reduced order model is used as is in the system simulations.

\section{System simulation}

\subsection{Improved storage tank model}

With reference to [13], the original storage tank description had states $T_{\mathrm{w}}, T_{\mathrm{cx}}$ and $T_{\mathrm{fx}}$ denoting well mixed storage tank water temperature, collector heat exchanger fluid temperature, and floor heating heat exchanger fluid, respectively. In the improved storage tank model, based on the concentrated model in Eqs. 14-16, will have states $T_{\mathrm{w}, \ell}, T_{\mathrm{w}, \mathrm{u}}, T_{\mathrm{cx}}$ and $T_{\mathrm{fx}}$. For the collector fluid in the heat exchanger:

$$
\begin{aligned}
\frac{d T_{\mathrm{cx}}}{d t}= & \frac{\dot{m}_{\mathrm{c}}}{m_{\mathrm{cx}}}\left(T_{\mathrm{c}}-T_{\mathrm{cx}}\right) \\
& -\frac{\left.U A\right|_{\mathrm{cx} 2 \mathrm{w}} \frac{x_{\mathrm{aux}}}{x_{\mathrm{w}}}}{m_{\mathrm{cx}} \hat{c}_{p, \mathrm{cx}}}\left(T_{\mathrm{cx}}-T_{\mathrm{w}, \ell}\right) \\
& -\frac{\left.U A\right|_{\mathrm{cx} 2 \mathrm{w}} \frac{x_{\mathrm{w}}-x_{\mathrm{aux}}}{x_{\mathrm{w}}}}{m_{\mathrm{cx}} \hat{c}_{p, \mathrm{cx}}}\left(T_{\mathrm{cx}}-T_{\mathrm{w}, \mathrm{u}}\right),
\end{aligned}
$$

for the floor fluid in heat exchanger:

$$
\begin{aligned}
\frac{d T_{\mathrm{fx}}}{d t}= & \frac{\dot{m}_{\mathrm{f}}}{m_{\mathrm{fx}}}\left(T_{\mathrm{f}}-T_{\mathrm{fx}}\right) \\
& -\frac{\left.U A\right|_{\mathrm{fx} 2 \mathrm{w}} \frac{x_{\mathrm{aux}}}{x_{\mathrm{w}}}}{m_{\mathrm{fx}} \hat{c}_{p, \mathrm{fx}}}\left(T_{\mathrm{fx}}-T_{\mathrm{w}, \ell}\right) \\
& -\frac{\left.U A\right|_{\mathrm{fx} 2 \mathrm{w}} \frac{x_{\mathrm{w}}-x_{\mathrm{aux}}}{x_{\mathrm{w}}}}{m_{\mathrm{fx}} \hat{c}_{p, \mathrm{fx}}}\left(T_{\mathrm{fx}}-T_{\mathrm{w}, \mathrm{u}}\right),
\end{aligned}
$$

and for the water in the storage tank:

$$
\begin{aligned}
\frac{d T_{\mathrm{w}, \ell}}{d t}= & \frac{\dot{m}_{\mathrm{hw}}}{m_{\mathrm{w}} \frac{x_{\mathrm{aux}}}{x_{\mathrm{w}}}}\left(T_{\mathrm{w}, \mathrm{i}}-T_{\mathrm{w}, \ell}\right) \\
& +\frac{\left.U A\right|_{\mathrm{cx} 2 \mathrm{w}}}{m_{\mathrm{w}} \hat{c}_{p \mathrm{w}}}\left(T_{\mathrm{cx}}-T_{\mathrm{w}, \ell}\right) \\
& +\frac{\left.U A\right|_{\mathrm{fx} 2 \mathrm{w}}}{m_{\mathrm{w}} \hat{c}_{p \mathrm{w}}}\left(T_{\mathrm{fx}}-T_{\mathrm{w}, \ell}\right) \\
& -\frac{\left.U A\right|_{\mathrm{w} 2 \mathrm{a}_{2}}}{m_{\mathrm{w}} \hat{c}_{p \mathrm{w}}}\left(T_{\mathrm{w}, \ell}-T_{\mathrm{a}_{2}}\right) \\
\frac{d T_{\mathrm{w}, \mathrm{u}}}{d t}= & \frac{\dot{m}_{\mathrm{hw}}}{m_{\mathrm{w}} \frac{x_{\mathrm{w}}-x_{\mathrm{aux}}}{x_{\mathrm{w}}}}\left(T_{\mathrm{w}, \ell}-T_{\mathrm{w}, \mathrm{u}}\right) \\
& +\frac{\left.U A\right|_{\mathrm{cx} 2 \mathrm{w}}}{m_{\mathrm{w}} \hat{c}_{p \mathrm{w}}}\left(T_{\mathrm{cx}}-T_{\mathrm{w}, \mathrm{u}}\right) \\
& +\frac{\left.U A\right|_{\mathrm{fx} 2 \mathrm{w}}}{m_{\mathrm{w}} \hat{c}_{p \mathrm{w}}}\left(T_{\mathrm{fx}}-T_{\mathrm{w}, \mathrm{u}}\right) \\
& -\frac{\left.U A\right|_{\mathrm{w} 2 \mathrm{a}_{2}}}{m_{\mathrm{w}} \hat{c}_{p \mathrm{w}}}\left(T_{\mathrm{w}, \mathrm{u}}-T_{\mathrm{a}_{2}}\right) \\
& +\frac{1}{m_{\mathrm{w}} \frac{x_{\mathrm{w}}-x_{\mathrm{aux}}}{x_{\mathrm{w}}} \hat{c}_{p \mathrm{w}}} \dot{Q}_{\mathrm{aux}} .
\end{aligned}
$$

\subsection{Ventilation energy recovery}

With reference to [13], the improved building model only needs a change in the description of the air temperature, 


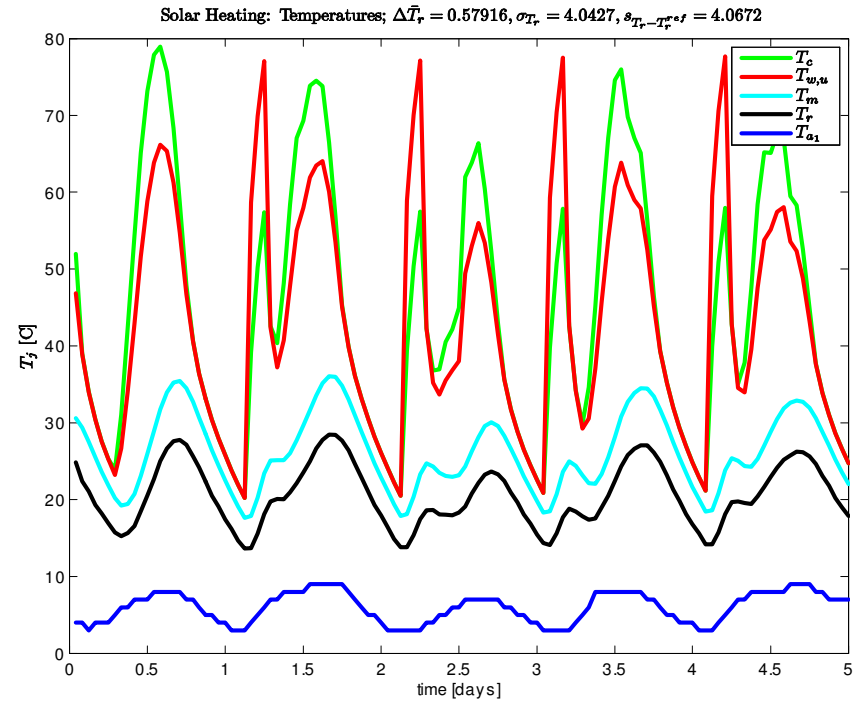

Figure 16: Temperatures at various positions in the system with realistic disturbance inputs.

which changes to

$$
\begin{aligned}
\frac{d T_{\mathrm{r}}}{d t}= & \frac{\dot{m}_{\mathrm{r}, \mathrm{i}}}{m_{\mathrm{r}}}\left(T_{\mathrm{a}_{1}}-T_{\mathrm{r}}\right) \times\left(1-\eta_{\mathrm{v}}\right) \\
& +\frac{\left.U A\right|_{\mathrm{m} 2 \mathrm{r}}}{m_{\mathrm{r}} \hat{c}_{\mathrm{p}, \mathrm{r}}}\left(T_{\mathrm{m}}-T_{\mathrm{r}}\right) \\
& -\frac{\left.U A\right|_{\mathrm{r} 2 \mathrm{a}_{1}}}{m_{\mathrm{r}} \hat{c}_{\mathrm{p}, \mathrm{r}}}\left(T_{\mathrm{r}}-T_{\mathrm{a}_{1}}\right),
\end{aligned}
$$

where zero ventilation energy recovery as used in [13] is equivalent to setting $\eta_{\mathrm{v}}=0$, while complete energy recovery is equivalent to setting $\eta_{\mathrm{v}}=1$. In the subsequent simulations, $\eta_{\mathrm{v}}=0.5$, which is unrealistically low.

\subsection{Simulation}

Except for the obvious changes of model parameters necessitated by the changes in ventilation heat recovery and storage tank, the model parameters, operating conditions, and disturbances are as in [13].

Figures 16-18 indicate the operation of the system when using a thermostat controller to control the room temperature to ca. $20^{\circ} \mathrm{C}$, and can be compared to the results in [13].

Using the improved model in this work with thermostat control, the standard deviation of the offset from the reference room temperature is $s_{T_{\mathrm{r}}-T_{\mathrm{r}}}^{\text {ref }}=4.1^{\circ} \mathrm{C}$, with a mean auxiliary heating of $\overline{\dot{Q}}_{\text {aux }} 0.4 \mathrm{~kW}$. The ventilation heat loss seems to be $\overline{\dot{Q}}_{\text {vent }} \approx 1.0 \mathrm{~kW}$. With the original model of [13], the similar numbers were $s_{T_{\mathrm{r}}-T_{\mathrm{r}}^{\text {ref }}}^{2014}=3.8^{\circ} \mathrm{C}$, $\overline{\dot{Q}}_{\text {aux }}^{2014} 1.17 \mathrm{~kW}$ and $\overline{\dot{Q}}_{\text {vent }} \approx 1.5 \mathrm{~kW}$. Obviously, these numbers can not be used to tell which model is best. However, it is clear that the energy consumption is reduced with the new model: this is a result of a combination of ventilation heat integration and allowing for temperature distribution in the storage tank $\mathrm{k}^{4}$. The fact that the temperature

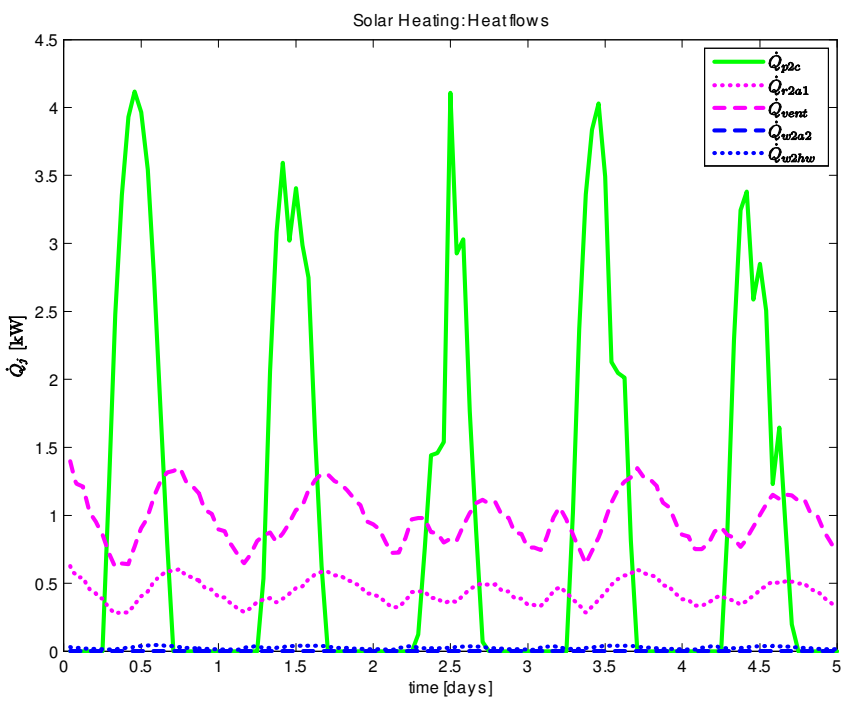

Figure 17: Heat flows at various positions in the system with realistic disturbance inputs.

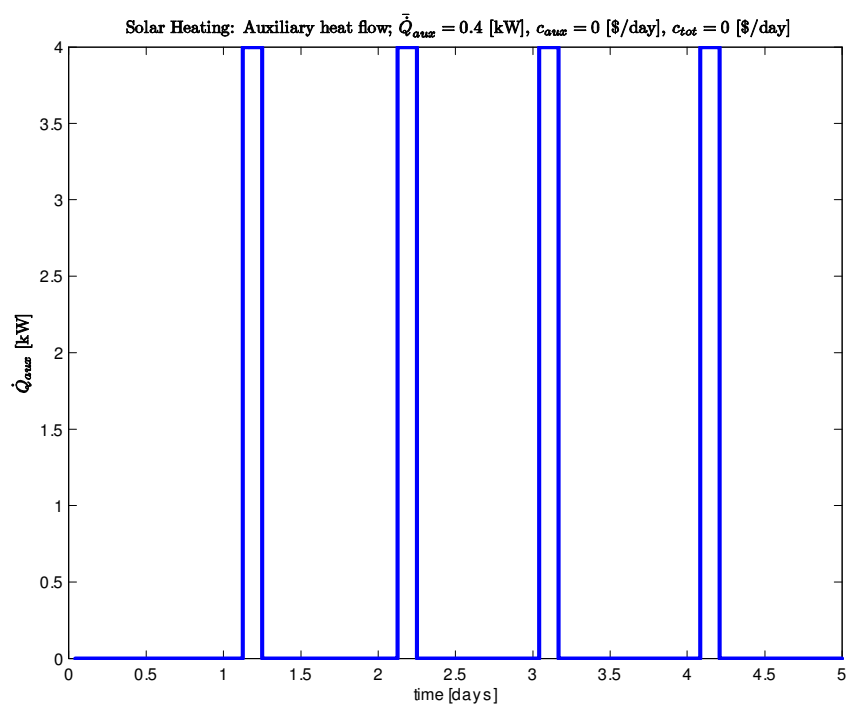

Figure 18: Auxiliary heat input to storage tank using thermostat controller.

\footnotetext{
${ }^{4}$ Temperature distribution/stratification implies less entropy loss due to mixing, and thus a higher exergy = available energy.
} 
variation increases in the improved model simply reflects the fact that for the given conditions, the solar energy is too plentiful to allow good control: to improve the control, it is necessary to be able to reduce the heat flow from the collector. In these simulations, the efficiency of the ventilation heat integration is set to $\eta_{\mathrm{v}}=0.5$. In simple ventilation heat integration systems, a realistic efficiency factor is typically $\eta_{\mathrm{v}}=0.7$ or so. With heat pumps, $\eta_{\mathrm{v}}$ can be even higher, at the cost of a slightly increased electricity consumption.

\section{Conclusions}

This paper discusses two improvements in a previously published model of solar heating of buildings applied to on-line control and optimization: inclusion of energy recovery from ventilation, and a more realistic water storage tank model. Simulation results of a 1D distributed storage tank model seem to indicate that a two compartment model is sufficiently accurate for control design, although variation in the hot water consumption ideally requires a two compartment model with varying volumes for the two compartments this is similar to using a thermocline tracking algorithm. Simulation results of the complete system with a thermostat controller verifies expected changes in the system behavior. However, good control of the system can not be expected unless it is also possible to reduce the influence of the solar irradiance: the peak irradiance is too strong, so that the room temperature becomes too high.

Although the model has been improved, future improvements are possible. Here, it is important to make a distinction between improvements which are necessary to make the model realistic, and design changes necessary to make the system better controllable. The list of improvements from the introduction to this paper are still relevant. A higher ventilation heat recovery should be used, and it should be considered to introduce thermocline tracking/variable zone volumes in the storge tank. Also, it is possible that the heat exchanger for the floor heating system should not pass through the hot zone.

To improve controllability, it may be necessary to reduce the circulation of the solar collector fluid.

\section{References}

[1] Arachchige, D.D.K. (2014). An Approach to Day Ahead Forecasting of Solar Irradiance with an Application to Energy Gain in Solar Thermal Collectors. M.Sc. thesis, University of Agder, Faculty of Engineering and Science, Grimstad.

[2] Bayón, R., and Rojas, E. (2013). "Simulation of thermocline storage for solar thermal power plants: From dimensionless results to prototypes and real-size tanks". International Journal of Heat and Mass Transfer, Vol. 60, pp. 713721. http://dx.doi.org/10.1016/j.ijheatmasstransfer. 2013.01.047.
[3] Defra (2008). Measurement of Domestic Hot Water Consumption in Dwellings. Department for Environment, Food and Rural Affairs (Defra), UK.

[4] de Oliveira , V., Jäschke, J., and Skogestad, S. (2013). "Dynamic online optimization of a house heating system in a fluctuating energy price scenario". Preprints of the 10th IFAC International Symposium on Dynamics and Control of Process Systems, The International Federation of Automatic Control, December 18-20, 2013, Mumbai, India, pp. 463-468.

[5] Duffie, J.A., and Beckman, W.A. (2013). Solar Engineering of Thermal Processes, 4th edition. John Wiley \& Sons, Hoboken, NJ.

[6] Durão, B., Joyce, A., Farinha Mendes, J. (2014). “Optimization of a seasonal storage solar system using $\mathrm{Ge}$ netic Algorithms". Solar Energy, Vol. 101, pp. 160166.

[7] Eicker, U. (2014). Energy Efficient Buildings with Solar and Geothermal Resources. John Wiley \& Sons Ltd., Chichester, UK. ISBN 9781118352243.

[8] Han, Y.M., Wang, R.Z., and Dai, Y.J. (2009). “Thermal stratification within the water tank". Renewable and Sustainable Energy Reviews, Vol. 13, pp. 10141026. doi:10.1016/j.rser.2008.03.001.

[9] Cheng Hin, J.N., and Zmeureanu, R. (2014). "Optimization of a residential solar combisystem for minimum life cycle cost, energy use and exergy destroyed". Solar Energy, Vol. 100, pp. 102-113.

[10] Holth, E. (2009). Model Predictive Control of mixed solar and electric heating. MSc thesis, NTNU, Norway.

[11] Jordan, U., and Vajen, K. (2000). "Influence of the DHW load profile on the fractional energy savings: a case study of a solar combi-system with trnsys simulations". Solar Energy, Vol. 69, Nos. 1-6, pp. 197-208.

[12] Kratzenberg, M.G., Beyer, H.G., and Colle, S. (2006). "Uncertainty calculation applied to different regression methods in the quasi-dynamic collector test". Solar Energy, Vol. 80, pp. 1453-1462

[13] Lie, B., Pfeiffer, C., Skeie, N.-O., Beyer, H.G. (2014). "Models for Solar Heating of Buildings". Proceedings, 55th International Conference of Scandinavian Simulation Society (SIMS 2014), October 21-22 2014, Aalborg University, Denmark. Published by Linköping Electronic Press, www.ep.liu.se/ecp/108/ecp14108.pdf, pp. 28-38

[14] Lie, B., Pfeiffer, C., Beyer, H.-G. (2014). "Using history based irradiance forecasts for supporting the predictive control of solar thermal systems". Proceedings, EuroSun 2014, September 16- 19, Aix-lesBains, France. 
[15] Perera., D.W.U., Pfeiffer, C., and Skeie, N.-O. (2014). "Modelling the heat dynamics of a residential building unit: Application to Norwegian buildings". Modeling, Identication and Control, Vol. 35, No. 1, pp. 43-57, ISSN 1890-1328. doi:10.4173/mic.2014.1.4.

[16] Perera., D.W.U., Pfeiffer, C., and Skeie, N.-O. (2014). "Modeling and simulation of multi zone buildings for better control”. Proceedings, SIMS 2014, Aalborg, Denmark, October 21-22, 2014.

[17] Pichler, M.F., Lerch, W., Heinz, A., Goertler, G., Schranzhofer, H., Rieberer, R. (2014). "A novel linear predictive control approach for auxiliary energy supply to a solar thermal combistorage". Solar Energy, Vol. 101, pp. 203-219.

[18] Powell , K.M., and Edgar, T.F. (2012). "Modeling and control of a solar thermal power plant with thermal energy storage". Chemical Engineering Science, Vol. 71, pp. 138-145.

[19] Powell , K.M., and Edgar, T.F. (2013). "An adaptivegrid model for dynamic simulation of thermocline thermal energy storage systems". Energy Conversion and Management, Vol. 76, pp. 865-873. http://dx.doi.org/10.1016/j.enconman.2013.08.043.

[20] Saleh, A.M. (2012). Modeling of Flat-Plate Solar Collector Operation in Transient States. M.Sc. thesis, Purdue University, Indiana.

[21] Zima, W., and Dziewa, P. (2010). "Mathematical modelling of heat transfer in liquid flat-plate solar collector tubes". Archives of Thermodynamics, Vol. 31, No. 2, pp. 45-62. doi: 10.2478/v10173-010-0008-7. 